This item was submitted to Loughborough's Research Repository by the author.

Items in Figshare are protected by copyright, with all rights reserved, unless otherwise indicated.

\title{
An overview of managed futures' performance: 1983 to post-2008 credit crisis
}

PLEASE CITE THE PUBLISHED VERSION

http://dx.doi.org/10.1002/9781118656501.ch22

PUBLISHER

(C) John Wiley and Sons

VERSION

AM (Accepted Manuscript)

\section{PUBLISHER STATEMENT}

This work is made available according to the conditions of the Creative Commons Attribution-NonCommercialNoDerivatives 4.0 International (CC BY-NC-ND 4.0) licence. Full details of this licence are available at: https://creativecommons.org/licenses/by-nc-nd/4.0/

\section{LICENCE}

CC BY-NC-ND 4.0

\section{REPOSITORY RECORD}

Tee, Kai-Hong. 2019. "An Overview of Managed Futures' Performance: 1983 to Post-2008 Credit Crisis". figshare. https://hdl.handle.net/2134/17101. 


\title{
Chapter 21 Performance of Managed Futures: 1983 to the Post-2008 Crisis Period
}

KAI-HONG TEE

Senior Lecturer in Finance, Loughborough University

KEYWORDS: Managed futures, Chicago Mercantile Exchange, market timing; performance persistence, post-2008 crisis, diversification benefits, correlations, allocation mechanism.

\begin{abstract}
The growth of the managed futures industry increased dramatically in the late 1970s after the introduction of the world's first financial futures contracts (foreign currency futures) by the Chicago Mercantile Exchange in 1972. The first published academic research on the performance of managed futures appeared in the 1980s. Researchers who adopted similar performance metrics to assess managed futures in different time periods also reached similar conclusions as earlier studies about the benefits of managed futures. Some recent studies address the issues of performance persistence and market timing ability of managed futures traders. Following the onset of the financial crisis of 2007-2008, researchers also reassessed the diversification benefits of managed futures and the low correlations of their returns with those of stocks and bonds. Evidence reaffirmed that the favorable characteristics of managed futures investments were useful for investors looking for a "crisis alpha" for their portfolios in periods with high market volatility.
\end{abstract}

\section{INTRODUCTION}

In the United States, organized futures markets have been in existence since the mid-19 ${ }^{\text {th }}$ century following the official opening of the Chicago Board of Trade (СBOT) in 1848, where futures contracts started to trade with grains as the underlying commodity. These futures contracts served a good purpose for grain producers and dealers as a protection against adverse future price movements. The futures markets brought together commercial hedgers 
and speculators in an open, competitive marketplace to determine an asset's price at a single point in time. As these markets became increasingly complex due to the introduction of new futures contracts, more sophisticated strategies, and international market opportunities, users of the futures markets sought more specialized professional advice in managing their futures market assets. This change is especially noticeable after the substantial growth in futures trading in the early $20^{\text {th }}$ century when newly established exchanges introduced a variety of commodity contracts. The introduction of the world's first financial futures contracts (foreign currency futures) by the Chicago Mercantile Exchange (CME) in 1972 was also an important landmark in futures trading. Other financial futures contracts (e.g., interest rate and stock index futures) appeared in the late 1970 s and 1982, respectively.

The successful introduction of futures contracts to encompass equity indices, interest rates, currencies, options, and conventional commodities as well as the globalization of futures trading have expanded the scope of investment possibilities and thus created new profit opportunities for a new type of market participants - managed futures investors. Managed futures refers to the trading of futures and forwards contracts on commodities and financial instruments by either institutions or trading advisors who manage assets in these markets on behalf of their clients. Hence, the managed futures industry consists of professional money managers who manage clients' assets on a systematic or discretionary basis, using global futures and options markets as investment media. Managing clients' assets on a systematic basis involves the managers use of technical trading systems to exploit investment opportunities for the clients' money, while those managed on a discretionary basis involves managers' value judgement on market conditions usually without any trading systems, but still involving some statistical information to help make decision for investing clients' money.

One major incentive for managed futures investments appears to stem from their ability to offer risk reduction through diversification while still offering returns comparable to other traditional investments (e.g., domestic and international equity indexes). Research on traditional 
security markets shows that market prices react to unexpected changes in micro (e.g., earnings) or macro (e.g., interest rates and gross national product) information. Trading futures contracts based on forecasts of these fundamental variables may likewise result in positive return/risk tradeoffs. The importance of this research is that managed futures may allow investors to profit from market trends or unexpected changes in information in ways that are not easily available from other managed assets such as stock-based mutual funds. The differences occur because the cash market's transaction costs and institutional restrictions on short selling and leverage make engaging in strategies that involve short positions unprofitable for mutual fund managers. Hence, managed futures can, in principle, enable an investor to capture those returns available in the spot market more cheaply (e.g., replicate cash indexes with lower transaction costs) and capture opportunities not easily found in spot markets (e.g., the ability to sell short and to alter the degree of leverage in asset positions).

The growth of the managed futures industry increased dramatically in the late 1970s. While less than US $\$ 500$ million was invested in 1980, the total investment in managed futures exceeded US $\$ 120$ billion in 2005. Allocation of funds to managed futures increased because of the investors' desire for higher returns and more effectively managed portfolio risk. The Commodity Futures Trading Commission (CFTC) defines a commodity trading advisor (CTA) as any person, who, for compensation or profit, directly or indirectly advises others regarding the buying or selling of commodity futures and/or option contracts (Ates and Wang, 2008). It defines a commodity pool operator (CPO) as any individual or firm that operates or solicits funds for a commodity pool. Typically, a number of individuals contribute funds to form a commodity pool. In the United States, a commodity pool is usually organized as a limited partnership. Most CPOs hire independent CTAs to make daily trading decisions. The CPO may distribute the investment directly or act as a wholesaler to a broker/dealer.

Investing in managed futures can occur in three ways. First, investors can purchase shares of public commodity funds, which are similar to equity or bond mutual funds except that 
they invest in futures contracts. Public funds provide a way for small (retail) investors to participate in an investment vehicle usually reserved for large investors because they typically have the lowest minimum investment requirements. Second, investors can place funds with a private CPO who pools all investors' funds together and retains one or more professional traders, i.e., CTAs, to manage the pooled funds. Pools have higher minimum investment requirements than public funds. Third, investors can place their funds directly with one or more CTAs to manage their funds on an individual basis. The minimum investment required by CTAs typically is set higher than public commodity funds and private CPOs.

This chapter discusses the empirical evidence about the performance of managed futures spanning a period of three decades as found in the extant literature. The chapter divides periods of studies into earlier, later, and recent studies. The chapter also discusses and reevaluates the role of managed futures after the financial crisis of $2007-2008$. The final section provides a summary and conclusions.

\section{Performance Assessment of Managed Futures as a Stand-alone Investment}

This section discusses the performance of managed futures in the 1980s, 1990s, and 2000s. Each of the periods has some distinctively different approaches for assessing performance. Studies in the 1980s set a benchmark for a performance metric used to assess managed futures. Representative studies in the 1990s used more comprehensive datasets and expanded the scope of research to help gain more insights about the performance of managed futures. Studies in 2000s built on established research in the 1980s and 1990s and focused on further issues such as performance persistence and market timing ability of managed futures traders.

\section{Earlier Studies in the 1980s}

Lintner (1983) is perhaps the first academic to undertake a study on managed futures. He finds that managed futures are an attractive investment vehicle. Yet, later studies such as Elton, Gruber, and Rentzler (1987, 1990) and Irwin, Krukemyer, and Zulauf (1993) find that managed 
futures, at least as represented by public commodity funds, did not generate returns above the risk-free rate. Schneeweis, Savanayana, and McCarthy (1992) confirm earlier results relative to public commodity funds but limit the portfolio to 14 CTAs.

Lintner (1983) examines the performance of 15 individual CTAs and eight public commodity funds for the period July 1979 through December 1982. In computing the returns for the 15 CTAs, Lintner uses their composite performance (trading profits, including interest, net of all fees and commissions) as reported in their Disclosure Documents (reporting documents required by the CFTC). This composite performance includes results from all accounts traded by the CTA including public commodity funds, private pools, and individual managed accounts. As such, it offers a weighted return of the three different investment vehicles. Lintner also examines the monthly change in net asset value (NAV) of eight public commodity funds available to investors during the period studies. He shows the average monthly standard deviation of individual CTAs in his study was 2.72 percent, which was for those of public commodity funds. However, he also shows that diversifying an investment in managed futures by creating portfolios of CTAs lowers the risk of an investment in managed futures because the average correlation among the CTAs was only 0.285 .

Besides the stand-alone risk/return characteristics of CTAs, Lintner (1983) also analyzes the potential impact of adding managed futures to a portfolio of stocks (or stocks and bonds). First, he establishes that for the minimum risk portfolio of CTAs, the correlation coefficient with stocks is -0.07 and with bonds is 0.15 . For the minimum risk portfolio of public commodity funds, the correlation coefficient is 0.23 with stocks and 0.15 with bonds.

\section{Later Studies in the 1990s}

The earlier studies focused on correlations between managed futures returns and the returns to stocks and bonds. These earlier studies, however, appear to suffer from insufficient data due to 
the relatively shorter periods of the data availability. The later studies use a relatively larger dataset to further verify the findings of the early period.

Edwards and Liew (1999) use a more comprehensive set of data and extend the time of their examination period. They examine the monthly performance of CTAs, private pools, and public funds over the 1980-1996 period. Unlike previous studies, their research encompasses a much larger dataset. A total of 1,150 CTAs, 439 private commodity pools, and 619 public futures funds combine for 119,481 months of performance data: 60,054 for CTAs, 24,523 for commodity pools, and 34,904 for public funds. Managed Account Reports (MARs), which receive monthly performance information from participating CTAs, pools, and funds, provide the data.

Similar to earlier research by Lintner (1983) and Elton et al. (1987, 1990), Edward and Liew (1999) evaluate the performance of managed futures investments based on three stylized portfolios formed for CTAs, pools, and funds. These portfolios are as follows: (1) one-CTA, pool or fund portfolios, where a single CTA, pool or fund is randomly selected; (2) an equallyweighted market portfolio (EWMP) of all CTAs, pools, or funds in existence in a particular month, where an identical amount is invested in each CTA, pool or fund; and (3) a valueweighted portfolios (VWMP) of all CTAs, pools, or funds in existence in a particular month, where the weights reflect the proportion of total invested dollars managed by particular CTAs, pools or funds in the month. Edward and Liew compute monthly and yearly returns for each of these stylized portfolios.

In assessing the performance of these CTAs, pools, and funds, unlike all other previous studies reviewed, Edwards and Liew (1999) use the Sharpe ratio as a measure of risk-adjusted performance. They analyze returns in two sub-periods: 1982 to 1988 and 1989 to 1996.

Their results have five major implications. First, a VWMP of pools stands out as an attractive stand-alone investment, with respect to both alternative non-futures investments and other managed futures investments, especially during the 1989 to 1996 period. Although a 
VWMP of pools earned a somewhat lower average annual return than common stock during this period (13.9 percent compared with 16.0 percent), the lower volatility of pool returns resulted in a higher Sharpe ratio for the VWMP of pools of 0.955 . This performance is especially impressive given the extraordinarily high common stock returns during this period. A clear implication of these results is that private pool managers add value: they generate higher returns and Sharpe ratios than do most non-futures investments and outperform other managed futures returns.

Second, single-CTA, pool or fund portfolios or any type of public fund investment do not appear to make an attractive stand-alone investment. Single-CTA, pool or fund portfolios all had high return volatility, and public funds have low returns.

Third, the strong performance of a EWMP of CTAs during the 1982-1988 period should be given less credibility for two reasons. According to Edwards and Liew (1999), this period is subject to the greatest survivorship bias and CTA reported returns are highly sensitive to the exclusion rule used to control for self-selection bias.

Fourth, returns on all types of managed futures investments fell substantially in 1989 to 1996, compared to 1982 to 1988 , for reasons that remain unclear. A possible "data" explanation, according to Edwards and Liew (1999), is that returns in the 1982-1988 period may have been artificially inflated because of an upward survivorship bias, so that the elimination of this bias in the 1989-1996 period gives the appearance that returns fell during this latter period. Another possibility is that market conditions from 1989 to 1996 may not have been favorable to commodity traders. In particular, most commodity traders were "trend followers" to a greater or lesser degree. Further, commodity prices appeared to exhibit less trend-following behavior in 1989 to 1996 than in the earlier years, which increased the difficulty for traders to identify price trends and to capitalize on such trends. Finally, increased competition occurred 
during the 1989-1996 period. With more traders and more capital competing for trading profits, commodity markets may have become more efficient, resulting in lower returns.

Fifth, despite the decline in the level of returns between 1989 and 1996, the Sharpe ratio for a VWMP of pools rose significantly from 0.694 during the $1982-1988$ period to 0.955 during the 1989-1996 period. Lower return volatility offset the lower returns. However, this result was not replicated for a EWMP of pools or for either a EWMP or a VWMP of CTAs. Thus, large pools were more successful in managing risk than were either small pools or individual CTAs. Edward and Liew (1999) also provide an alternative way to view managed commodity funds as a separate asset class in a diversified portfolio. They then determine whether portfolio performance is significantly enhanced by including commodity funds in the portfolio.

Edward and Liew (1999) show the simple correlation coefficients between managed commodity fund returns and the returns on other asset classes are generally very low (typically below 0.10 ) and are often not significantly different from zero. Some correlations are even negative. For example, returns on a VWMP of pools are negatively correlated with S\&P 500 common stock returns in all time periods, although they are never significantly different from zero. The highest correlation observed for the $1982-1996$ period is 0.15 , which occurs between a VWMP of funds and long-term government bonds. Thus, including managed commodity funds in a diversified asset portfolio should provide diversification benefits.

\section{Recent Studies in the 2000s}

The later studies of managed futures performance verified those of the earlier studies. The research conducted by Edward and Liew (1999) is one of the major studies in the later period. Managed futures returns continue to be low and even more so for the CTA performances. One explanation that Edward and Liew attributed the low returns from 1989 to 1996 is a higher supply of CTAs in the market during that period. Research into correlations of managed futures returns with those of the stocks and bonds continues to show that they exhibit low correlation 
with each, further qualifying managed futures as good portfolio diversifiers. Recent studies of managed futures performance have moved into areas that investigate, for example, the performance persistence of CTAs. Gregoriou, Hubner, and Kooli (2010) focus on the issue of performance persistence. Given the inferior performance noted in earlier periods, the study's findings would be of interest particularly if a CTA generates not only low returns but also persistent performance.

Gregorious et al. (2010) note that the evidence of return persistence for managed futures in the literature is mixed but generally negative. Irwin, Zulauf, and Ward (1992), who examine 363 CTAs during the 1979-1989 period, find a lack of performance persistence when using past CTA returns to predict future returns. Irwin et al. (1993) examine commodity pools during the 1979-1990 period. Unlike the performance of CTAs investigated in Gregoriou et al., Irwin et al.'s research does not exhibit return persistence, even though they address some issues of market efficiency of the future market. As Gregoriou et al. note, Irwin (1994) focuses on individual CTAs and concurs with the previous finding, but offers little evidence of the predictability in average CTA returns.

In contrast, McCarthy, Schneeweis, and Spurgin (1996) find some evidence of performance persistence. However, their sample size of 56 CTAs is relatively small and their study only focuses on the 1985-1991 timeframe. These authors observe that multi-advisor managed futures funds display more persistence than single advisor CTAs (Schneeweis, Spurgin, and McCarthy, 1997). Brorsen (1998) investigates data from private and public funds and CTAs using various statistical methods such as regression analysis, Monte Carlo methods, and out-of-sample tests. He also finds limited evidence of performance persistence. The main drawback of each of these studies is the short examination period during the bull market, while not encompassing any sustained bear market environment.

According to Gregoriou et al. (2010), only a few attempts to study CTA performance and persistence use parametric models. A possible reason is that regression methods tested so far 
have hardly produced any satisfactory significance levels. Using the 1990-1999 period, Brorsen and Townsend (2002) find limited support for performance persistence using regression analysis.

Gregoriou et al. (2010) re-examine the performance of CTAs and compare their abnormal performances based on various models, as well as a category-specific model introducing asset-, option-, and moments-based factors. Taking more factors into account significantly raises the explanatory power of the model. In fact, nine out of 12 CTA categories significantly outperform the market. Multifactor models also do a good job of explaining CTA behavior of various categories. The average adjusted $R^{2}$ increases from 0.04 for the Carhart four-factor model to 0.31 for more complex multifactor models. The adjusted $R^{2} s$ of the 12 multifactor models range from 0.02 to 0.51 . Although the multifactor models may appear to explain a substantial part of the variation of CTA returns, a key explanatory piece is still missing.

Gregoriou et al. (2010) use monthly data for the 1995-2008 sample period for the following variables: $M k t$ (excess return of the market proxy), SMB (the factor-mimicking portfolio for size, i.e., small minus big), $H M L$ (the factor-mimicking portfolio for book-to-market equity), PRIVR (the factor-mimicking portfolio for the momentum effect), and Var, Skew, and Kurt (the factor mimicking portfolios for variance, skewness, and kurtosis, respectively). Furthermore, the study includes option-based factors such as at-the-money (ATM) call and put options, following the work of Fung and Hsieh (2001). These explanatory variables seem to adapt well only to a few CTAs as revealed by the adjusted $R^{2}$ values. For example, adjusted $R^{2}$ values for both currency CTA and financial/metal CTA are 0.51 but the value is only 0.40 for systematic CTA. The explanatory variables do not adapt well to discretionary CTAs with an adjusted $\mathrm{R}^{2}$ of only 0.02. Liang (2003), who in a similar study reports adjusted $R^{2} s$ ranging from 0.07 to 0.14 , concludes that CTAs are different from hedge funds or fund-of-funds in trading strategies in which those multifactor models have very low explanatory power for CTAs. 
Gregoriou et al. (2010) note some unresolved issues. For example, their findings show that CTAs still address challenges to performance measurement and indicate that more needs to be done to identify CTA performance drivers. The return-generating process also shows more than half of total variance is unexplained possibly indicating a high instability in CTA risk exposures. This finding warrants more research and understanding into what determines and drives CTAs' returns and risk exposures. The authors also examine the performance persistence of CTAs over different time periods. Similar to the work of Brown, Goetzmann, and Ibbotson (1999) and Agarwal and Naik (2002), Gregoriou et al. compare the performance measures in the current period on the performance measures in the previous period. They use $\alpha$ as a performance measure, which is defined as the return of a CTA following a particular strategy minus the average return for all CTAs following the same strategy.

Gregoriou et al. (2010) use a nonparametric method to investigate the issue of persistence in two consecutive periods. They construct a contingency table of winners and losers. A CTA is a winner if the $\alpha$ is greater than the median $\alpha$ of all CTAs following the same strategy in that period; otherwise, it is a loser. Persistence refers to the existence of CTAs that are winners in two consecutive periods (1-month, 3-month, 6-month, and 12-month periods), denoted by WW, or losers in two consecutive periods, denoted by LL. Similarly, winners in the first period and losers in the second period are denoted $W L$, and $L W$ denotes the reverse pattern. The authors define the cross-product ratio (CPR) as the product of repeat winners (WW) and repeat losers (LL) divided by the product of winners-losers (WL) and losers-winners $(L W)$, i.e., $(W W \times L L) /(L W \times W L)$. A CPR of one would support the hypothesis that the performance in one period is unrelated to that in another. A CPR greater than one indicates persistence; a value below one indicates that reversals in performance dominate the sample. The authors use chi-square statistics similar to Christensen (1990) to detect statistical 
significance of persistence. They also use the standard error of the natural logarithm of the CPR as given by Equation 21.1:

$$
\sigma_{\ln (C P R)}=\sqrt{\frac{1}{W W}+\frac{1}{W L}+\frac{1}{L W}+\frac{1}{L L}}
$$

The findings from Gregorious et al. (2010) show that a CTA displaying persistence over a horizon of at least three months is more likely to exhibit persistence over a longer period. However, most of these results do not stand the "acid test," which aims at assessing the relative performance persistence of a CTA by considering the ability of a CTA to stay in a top quartile rather than the top half of a category. Of all the CTAs assessed by the "acid test," the performance persistence of agricultural CTAs appears more robust to a change in testing conditions.

Kazemi and Li (2009) explore the sources of CTA returns. Their study investigates the market and volatility timing ability of CTAs and examines whether discretionary CTAs display different market timing skills from systematic CTAs. The goal of their study is to formally test the hypothesis as to whether trend-following CTAs possess timing ability due to the commonlyobserved similarities between market timers and trend followers. They also explore whether CTAs display market timing ability in those markets that are the focus of their trading strategy. Their research reports that previous studies such as Fung and Hsieh (2001) show that one important challenge in testing for the presence of market timing ability is that models employing traditional factors have low explanatory power for CTA returns, and, therefore, may be unable to detect the presence of market timing skills. Besides, the traditional indices that are based on equity and fixed-income markets may not include important risk factors such as those related to various currencies, commodities, or interest rates that are present in most CTA portfolios. Unlike previous studies, Kazemi and Li use a set of futures-related factors that are based on returns from the most heavily traded futures contracts. They find that these factors possess much higher explanatory power for CTA returns than traditional factors. 
Henriksson and Merton (1981) develop a test for market timing skills and assume that the mutual fund manager allocates capital between risk-free assets and equities based on forecasts of the future excess market returns. Busse (1999) extends the model to detect combined return and volatility timing. Kazemi and Li (2009) also apply this extension to test for CTAs' ability to time the best performing markets in each category of futures markets using Equation 21.2 as their model:

$$
r_{p, i+1}=\alpha_{i+1}+\sum_{j=1}^{k} \beta_{j} r_{j, t+1}+\sum_{i=1}^{n} D_{i} \max \left(\max \left(r_{1, t+1}, r_{2, t+1}, \ldots \ldots, r_{n, t+1}\right), 0\right)+\delta r_{m, t+1}\left(\sigma_{m, t+1}-\overline{\sigma_{m}}\right)+\varepsilon_{t+1}
$$

where $r_{p, i+1}$ is excess return on a CTA index; $r_{j, t+1}$ represents excess return on a futures contract; and $\sigma_{m, t+1}$ is stock market volatility, measured by end of the month VIX. VIX is the ticker symbol for the Chicago Board Options Exchange Market Volatility Index, which tracks the implied volatility of S\&P 500 index options. It represents a measure of the market's expectation of stock market volatility over the next 30-day period. If CTAs have both return and volatility timing ability, then this will be shown by a significantly positive coefficient for $D$ and significantly negative coefficients for $\delta$.

The results indicate that the coefficient estimates carry the expected signs for both discretionary and systematic CTA indices. The adjusted $R^{2}$ s are 0.16 and 0.29 , respectively. Both discretionary CTAs and systematic CTAs show ability in timing the best-performing markets among currency futures (represented by Euro, Japanese Yen, and British Pound). Not only are the timing coefficients statistically significant, but their magnitudes are also of economic significance. Due to their ability to time the best-performing markets, on average, CTAs are able to generate an extra return of 0.57 percent when a 1 percent change occurred in any currency futures market. Return timing results of CTAs from other categories and/or models found in Kazemi and Li (2009) show that almost all market timing regressions have higher explanatory power for systematic CTAs than for discretionary CTAs. 
Bhardwaj, Gorton, and Rouwenborst (2008) readdress the moderately low performance of CTAs' returns and explore possibilities that could explain such performance. They analyze the performance of all CTAs that voluntarily report to the Lipper-TASS database. To eliminate the influence of various biases induced by strategic returns reporting and database construction, the authors exclude more than 80 percent of the available observations. Specifically, they exclude 83,201 of the 102,393 available monthly observations on fund performance post-1993 and all returns before 1994. These corrections greatly influence inferences about CTA performance. Bhardwaj et al. estimate that between 1994 and 2007 the average bias-adjusted CTA returns after fees have been statistically indistinguishable from the average return on an investment in U.S. T-bills. Hence, they conclude that the average CTA has not created value for its investors. The authors compare their findings to those by Elton, Gruber, and Rentzler (1987, $1989,1990)$ who almost two decades earlier report that publicly-traded commodity funds did not create positive returns for investors. Bhardwaj et al. conclude that the combined evidence shows that managed futures have not performed well for the past 20 years.

Other findings from Bhardwaj et al. (2008) include empirical evidence on net returns and the charges of performance related fees of CTAs. Their methodology follows that of French (2008) in the construction of gross returns for managed futures funds in Lipper-TASS, using the reported net returns. The authors make two assumptions when implementing French's model: (1) fees accrue on a monthly basis and (2) high watermarks, when applicable, increase at the rate of return on T-bills. A high watermark applies when a managed futures manager only receives performance fees on that particular pool of invested money when its ending value is greater than its previous highest value. Should the investment drop in value, then the managers must bring it back above the previous highest value before they become eligible for performance fees again.

Bhardwaj et al. (2008) find that bias-adjusted gross returns of CTAs computed from their database amount to about 5.37 percent and 0.85 percent net of fees. A comparison of fees 
between hedge funds and CTAs also shows that CTAs appear to have higher management fees and slightly higher incentive fees than hedge funds. Management and incentive fees of CTAs average 2.15 percent and 19.5 percent, respectively, while corresponding fees of hedge funds are only 1.42 percent and 16.33 percent. The authors suggest that the demand for CTAs is possibly less performance-sensitive and more price inelastic. Investors might be investing in CTAs for perceived diversification benefits and mandates for alternative investments (e.g., pension funds) and end up staying invested despite facing poor performance.

\section{The Diversification Benefits of Managed Futures in Time of Market Crisis}

Diversification benefits of managed futures in the academic literature are based on the nature of the lack of observed correlation between managed futures returns and those of the traditional investment portfolios composed of bonds and equities. Studies by Lintner (1983) and Edwards and Liew (1999), as well as those by Kat (2002), Jensen, Johnson, and Mercer (2003), and Cerrahoglu (2005) show the risk reduction benefits of managed futures. Edwards and Caglayan (2001) examine the performance of various hedge funds and commodity fund investment styles during periods of both rising and falling stock prices. Understanding how different investment styles perform in bear stock markets is important. Research finds that commodity funds offer better downside risk protection than hedge funds.

Oberuc (1992), who focuses on the performance of managed futures outside the United States, provides a case for investors including managed futures in their traditional stock and equity portfolios. According to Oberuc (p. 329),

... after the stock market crash of October 1987, investors realized that pinning their hopes of portfolio protection on stock selection methodologies was not successful. Indeed, it was found that diversifying a portfolio across equities from multiple countries provided very little protection since most countries' stock markets crashed at the same time. If stock selection did not provide the key to protection against portfolio drawdowns, then just what is the answer? Investment theory tells us that diversification across multiple investments that are not fundamentally linked with each other is the key. Unfortunately, all stocks are tied together through their linkage to something often referred to as the "market line." This means that as the stock market goes down (as measured by any of a 
number of market indexes), most individual stocks also tend to go down at the same time. Therefore, stock diversification is of little value against portfolio loss.

Oberuc (1992) analyzes the effect of using managed futures in combination with investment portfolios in four European countries (the United Kingdom, Germany, France, and Switzerland) over the 1979-1989 period. His findings reveal that these portfolios, whether or not they use currency-hedged or unhedged managed futures, seem to perform significantly better (i.e., higher return given the same level of risk) than those portfolios that did not include managed futures. The superior performance largely results from the low correlation of managed futures and other stock assets' returns. The low correlation becomes particularly useful in diversifying portfolios during a market crash, i.e., the October 1987's stock market crash. Most existing studies fail to emphasize the benefit of using managed futures during periods of financial crisis as a means of diversifying risk for stock and bond portfolios.

According to the Hedge Funds Review (2011a), a website that surveys hedge funds investment activities, CTAs running managed futures programs experienced record inflows in 2010 based on data from BarclayHedge. Combined assets managed by CTAs reached $\$ 267.6$ billion at the end of 2010 , an increase of more than 25 percent from $\$ 213.6$ billion in 2009 . That increase makes managed futures the single-largest strategy in the hedge fund universe, representing almost 15 percent of industry assets, according to BarclayHedge data. Once again, the focus appears to be on managed futures as a source of uncorrelated returns that can help diversify a broader portfolio. These properties came to the forefront in 2008 when managed futures programs returned more than 14 percent, on average, despite large declines in global markets. In fact, the credit crisis and credit crunch during the financial crisis of 2007-2008 resulted in governments bailing out banks and the collapse of major hedge funds and prompted many to re-think the role of managed futures in a diversified portfolio.

Despite the relatively lower returns and higher fees reported in Bhardwaj et al. (2008), Kaminski (2011a) observes that managed futures investments styles have some desirable 
characteristics not commonly found in the rather aggressive hedge funds trading programs such as the global macro hedge funds. Kaminski comments that managed futures trade exclusively in the most liquid, efficient, and credit protected markets and their profitability must rely on those characteristics in order to obtain a competitive edge. Therefore, managed futures will not profit from credit exposures and/or illiquidity, which are commonly cited as risks and opportunities for most hedge fund strategies. Supporting the use of managed futures, Kaminski $(2011 \mathrm{~b}$, p. 1) contends that:

Following the onset of a market crisis, managed futures will be one of the few strategies able to adapt to take advantage of the persistent trends across the wide range of asset classes they trade. It is important also to note that managed futures are not about timing equity markets - it profits from a wide range of opportunities during market crises (this includes currencies, bonds, short rates, soft commodities, energies, metals, and equity indices). When equity markets are not in crisis, markets are highly competitive and efficient - especially futures markets. Strategies like hedge funds often provide seductive returns, but many researchers have pointed out that these strategies often contain hidden risks related to liquidity and credit exposures.

Kaminski (2011b) also maintains that managed futures are an offensive investment rather than a defensive investment. The author argues that tail-risk insurance such as a longdated, out-of-the-money puts on equity indexes, with potential for immense payoffs in the event of a crisis, provide little or no return outside the period of the event crisis because they are prohibitively expensive if purchased during a crisis. Therefore, successful implementation of such a strategy is highly dependent on market timing. As market timing tends to be difficult, Kaminski classifies such tail-risk insurance as being defensive. In the case of managed futures, she contends that a managed futures strategy is a highly adaptable, liquid strategy poised to take advantage of predictable trends during market-crisis events but also able to provide modest returns over time and even in the absence of market timing ability. On that basis, Kaminski describes managed futures as an offensive approach dealing with tail events.

A few points discussed by Kaminski (2011a, 2011b) are important to help investors reconsider using managed futures in the post-2008 crisis period. Conversely, Bhardwaj et al. 
(2008) contend that managed futures charge such high fees that investors may want to consider investing directly in the futures markets. However, without the expertise of the managed futures traders, investors may be unable to deliver returns comparable to those of managed futures specialist. Therefore, although arguments exist about the fees of managed futures investments, no comparative empirical studies are available concerning the costs of investing in managed futures.

A report from the Hedge Fund Review (2011b) describes the strategy adopted by managed futures as a divergent strategy. The report claims that around 70 percent of CTAs employ trend-following or momentum-based strategies. Trend-following strategies benefit from directional moves that reflect informational gaps, changes in sentiment, and supply and demand imbalances in markets, which partly explain the low correlation of CTA returns with those of the stock market.

The report also claims that investors should not necessarily expect trend-following strategies to generate large profits in every market crisis, although large movement in prices often imply profit opportunities for managed futures. An interview with David Rothberg, from Niagara Capital Partners based in Toronto, reported in the Hedge Fund Review (2011b, p. 1), contains the following comment:

Trend followers size positions and place stops based on volatility, Rothberg notes. A low volatility environment tilts the odds in favor of trends followers because it allows them to take bigger positions with tight stop losses. But if prices move swiftly in a high volatility regime, trend followers will not be able to take a large enough position to fully benefit from the move, assuming they are not caught on the wrong side of the trend in the first place.

Though the extent of volatility of market environment may affect the profitability of managed futures, appropriate allocation mechanism within equities portfolios are an important determinant. The proportion of managed futures investors committed to their equities portfolios therefore would affect overall portfolio performance. Tee (2009) relates the allocated proportion of managed futures to reflect investors' risk tolerance level and shows that using appropriate 
models in the asset allocation process can potentially lead to better returns for investors who include some managed futures funds in their equities portfolios.

\section{SUMMARY AND CONCLUSIONS}

In the academic literature, managed futures are normally referred to as "trend-followers" because investors use their proprietary trading models to capture trends in futures prices. They also take long or short positions in low transaction cost investment vehicles, such as in futures contracts, in an attempt to benefit from trends in commodity prices, exchanges rates, interest rates, and equity markets, similar to many other alternative investments such as the hedge funds. As a result, CTAs are also listed as a strategy of hedge funds with their style named "managed futures." Over the past 20 years, empirical evidence generally shows that the performance of managed futures is, on average, similar to returns on risk-free rates such U.S. Treasury bills. Bhardwaj et al. (2008) find that between 1994 and 2007 managed futures funds average annual returns of 5.37 percent after adjusting for biases and before fees. They question why investors are still interested in managed futures despite their low returns and high fees. The authors explain the low returns as resulting from the supply of the inflow of funds to the managed futures sector, as one of the reasons. This argument is similar to Edwards and Liew (1999), who observe greater competition in the industry between 1989 and 1996. With more traders and capital competing for trading profits, commodity markets may have become more efficient and resulted in lower returns. Kazemi and Li (2009) provide some evidence of managed futures timing the futures markets, implying that the time-series price movement of futures securities and assets affects the returns of managed futures. This finding, however, does not adequately explain the low returns of managed futures funds.

Chen, Neill, and Zhu (2005) report that the key foundation for futures returns, as posited by some practitioners and academics, is the risk transfer function of the futures market itself (Kritzman, 1993; Lightner, 2003; Spurgin, 2003). Some commercial market participants such as 
hedgers are willing to pay the equivalent of an insurance premium to non-commercial participants (i.e., investors) for assuming risk. In the aggregate and over the long term, hedgers are willing to act consistently to transfer risk, even if they expect the spot markets to move in their favor, and in doing so, pay a net positive insurance premium. As providers of liquidity, investors receive this premium in the form of net trading profits. Unlike hedgers, investors in the futures markets regard "derivatives" as an asset class. They trade for profit-making purposes instead of hedging exposure of an underlying asset. Thus, the trading strategy should accommodate the trend that hedgers must follow in order to continuously and effectively transfer risk. The futures markets for trading managed futures are regulated, though the performances of managed futures traders or CTAs are not as regulated as the markets in which they participate. This trading arena differs from investment trusts or closed end funds that are listed on a stock exchange. Therefore, information may not be as complete as it should be in order to evaluate whether the performance of managed futures is correlated with future price movements. However, the number and type of the CTAs and hedgers in the future markets may affect the performance of managed futures. This relationship differs from one type of futures instrument to another, as liquidity tends to differ among derivative securities.

The diversification benefits of managed futures are based on the lack of observed correlation between managed futures returns and traditional investment portfolios composed of bonds and equities. Kat (2002), Jensen et al. (2003), and Cerrahoglu (2005) provide evidence of the risk-reduction benefits of managed futures. Interestingly, the diversification benefits of managed futures again attracted huge attention after the financial crisis of 2007-2008. Thus, the fact that managed futures tend to trade in liquid markets becomes a favorable factor. Kaminski (2011a, 2011b) terms managed futures as "crisis alpha," showing how it potentially adds value to a portfolio in market crisis. Researchers find using managed futures in this way is similar to that of the insurance-style strategies, with the latter often being criticized as costly. Others contend that directly investing in futures or commodity markets may be better for 
investors as they can avoid the higher fee structure of managed futures. However, no empirical comparative studies on the costs of investing in managed futures support the claim. Due to the low correlations of managed futures' returns with the stock and bonds' assets and despite relatively lower returns, the amount of capital to be invested in managed futures (either as stand-alone or for diversification purpose) has become an important issue, and even more so when markets are volatile. The extent of market volatility could affect the profits of managed futures according to report in Hedge Fund Review (2011b). A precise study on the performance persistence of managed futures during market crises is therefore an important area for future researchers to investigate. Such research could provide new findings about the performance characteristics of managed futures. Researchers should also investigate the issue involving the extent to which the persistence of performance justifies investing in managed futures during times of market crisis. This issue is important given that the academic literature often documents the relatively low returns generated by managed futures.

\section{DISCUSSION QUESTIONS}

1. Discuss the development of the managed futures industry. What are the various ways to invest in managed futures?

2. Discuss the possible sources of returns of managed futures' investments.

3. Explain the merits of investing in managed futures during times of equity market crisis.

4. What considerations are important when considering whether to include managed futures as part of an equity portfolio? 


\section{REFERENCES}

Agarwal, Vikas, and Narayan Y. Naik. 2002. "Multi-Period Performance Persistence Analysis of Hedge Funds." Journal of Financial and Quantitative Analysis 35:3, 327-342.

Ates, Aysegul, and George H. K. Wang. 2008. "Managed Futures." In Hung-Gay Fung, Xiaoqing Eleanor Xu, and Jot Yau, ed., Advances in International Investments: Traditional and Alternative Approaches, 213-214. Singapore: World Scientific Publishing Co. Pte Ltd. Bhardwaj, Geetesh, Gary B. Gorton, and K. Geert Rouwenhorst. 2008. "Fooling Some of the People All of the Time: The Inefficient Performance and Persistence of Commodity Trading Advisors." Working Paper, Yale International Center for Finance, Yale University.

Brorsen, B. Wade. 1998. "Performance Persistence for Managed Futures." Working Paper, Oklahoma State University.

Brorsen, B. Wade, and John Townsend. 2002. "Performance Persistence for Managed Futures." Journal of Alternative Investments 4:4, 57-61.

Brown, Stephen J., William N. Goetzmann, and Roger G. Ibbotson. 1999. "Offshore Hedge Funds Survival and Performance 1989-2005." Journal of Business 72:1, 91-117.

Busse, Jeffrey. A. 1999. "Volatility Timing in Mutual Funds: Evidence from Daily Returns." Review of Financial Studies 12:5, 1009-1041.

Cerrahoglu, Burak. 2005. "The Benefits of Managed Futures 2005 Update." Working Paper, Center for International Securities and Derivatives Markets, Isenberg School of Management, University of Massachusetts - Amherst.

Chen, Peng, Christopher O'Neill, and Kevin Zhu. 2005. "Managed Futures and Asset Allocation." Working Paper, Ibbotson Associates.

Christensen, Ronald. 1990. Log-Linear Models. New York: Springer.

Edwards, Franklin R., and Mustafa O. Caglayan. 2001. "Hedge Fund and Commodity Fund Investments in Bull and Bear Markets." Journal of Portfolio Management 24:7, 97-108. 
Edwards, Franklin R., and Jimmy Liew. 1999. "Managed Commodity Funds." Journal of Futures Markets 19:4, 377-411.

Elton, Edwin J., Martin J. Gruber, and Joel C. Rentzler. 1987. "Professionally Managed Publicly Traded Commodity Funds." Journal of Business 60:2, 175-199.

Elton, Edwin J., Martin J. Gruber, and Joel C. Rentzler. 1989. "New Public Offerings, Information, and Investor Rationality: The Case of Publicly Offered Commodity Funds." Journal of Business 62:1, 1-15.

Elton, Edwin J., Martin J. Gruber, and Joel C. Rentzler. 1990. "The Performance of Publicly Offered Commodity Funds." Financial Analysts Journal 46:4, 23-30.

French, Kenneth R. 2008. "The Cost of Active Investing." Social Science Research Network Working Paper Series. Available at SSRN http://ssrn.com/abstract=1105775.

Fung, William, and David Hsieh. 2001. "The Risk in Hedge Fund Strategies: Theory and Evidence from Trend-Followers." Review of Financial Studies 14:2, 313-341.

Gregoriou, Greg H., Georges Hubner, and Maher Kooli. 2010. "Performance and Persistence of Commodity Trading Advisors." Journal of Futures Markets 30:8, 725-252.

Hedge Fund Review. 2011a. "Managed futures on the Rise as Investors chase Diversification." Available at http://www.hedgefundsreview.com/hedge-fundsreview/feature/2035509/managed-futures-rise-investors-chase-diversification Hedge Fund Review. 2011b. "CTA/Managed Futures Hedge Fund Strategies Profit as Volatility Picks Up." Available at http://www.hedgefundsreview.com/hedge-fundsreview/feature/2108244/cta-managed-futures-hedge-fund-strategies-profit-volatility-picks. Henriksson, Roy D., and Robert G. Merton. 1981. "On Market Timing and Investment Performance II: Statistical Procedures for Evaluating Forecasting Skills." Journal of Business $54: 4,513-533$. 
Irwin, Scott H. 1994. "Further Evidence on the Usefulness of CTA Performance Information in Public Commodity Pool Prospectuses and a Proposal for Reform." In Don M. Chance and Robert R. Trippi, ed., Advances in Futures and Options Research, 251-265. Greenwich, CT: JAI Press.

Irwin, Scott H., Terry R. Krukemeyer, and Carl R. Zulauf. 1993. "Investment Performance of Public Commodity Pools: 1979-1990.” Journal of Futures Markets 13:7, 799-820.

Irwin, Scott H., Carl R. Zulauf, and Barry W. Ward. 1992. "The Predictability of Managed Futures Returns." Journal of Derivatives 2:2, 20-27.

Jensen, Gerald R., Robert R. Johnson, and Jeffrey M. Mercer. 2003. "The Time Variation in the Benefits of Managed Futures." Journal of Alternative Investments 5:4, 41-50.

Kaminski, Kathryn. 2011a. "In Search of Crisis Alpha: A Short Guide to Investing in Managed Futures." CME Group Education.

Kaminski, Kathryn. 2011b. "Offensive or Defensive? Crisis Alpha vs. Tail Risk Insurance.” Working Paper, RPM Risk and Portfolio Management.

Kat, Harry M. 2002. "Managed Futures and Hedge Funds: A Match Made in Heaven." Working Paper, Cass Business School, City University, London.

Kazemi, Hossein, and Ying Li. 2009. "Market Timing of CTAs: An Examination of Systematic CTAs vs. Discretionary CTAs." Journal of Futures Markets 29:11, 1067-1099.

Kritzman, Mark. 1993. "The Optimal Currency Hedging Policy with Biased Forward Rates." Journal of Portfolio Management 19:4, 94-100.

Liang, Bing. 2003. "The Accuracy of Hedge Fund Returns." Journal of Portfolio Management $29: 3,111-121$.

Lightner, Charles R. 2003. "A Rationale for Managed Futures.” Technical Analysis of Stocks \& Commodities 17:3, 138-143. 
Lintner, John V. 1983. "The Potential Role of Managed Futures Accounts (and/or Funds) in Portfolios of Stocks and Bonds." Presentation to the Annual Conference of the Financial Analysts Federation in Managed Futures, Toronto, Canada.

McCarthy, David, Thomas Schneeweis, and Richard Spurgin. 1996. "Survivor Bias in Commodity Trading Performance." Journal of Futures Markets 16:7, 757-772.

Oberuc, Richard E. 1992. "How to Diversify Portfolios of Euro-Stocks and Bonds with Hedged U.S. Managed Futures." Presentation at the First International Conference on Futures Money Management, May, Geneva, Switzerland.

Schneeweis, Thomas, U. Savanayana, and David McCarthy. 1992. "Multi-Manager Commodity Portfolios: A Risk/Return Analysis." In Charles B. Epstein, ed., Managed Futures in the Institutional Portfolio, 81-102. New York: John Wiley \& Sons, Inc.

Schneeweis, Thomas, Richard Spurgin, and David McCarthy. 1997. "Informational Content in Historical CTA Performance." Journal of Futures Markets 17:3, 317-339.

Spurgin, Richard. 2003. "Sources of Return in Managed Futures." Working Paper, Center for International Securities and Derivatives Markets, Isenberg School of Management.

Tee, Kai-Hong. 2009. “The Effect of Downside Risk Reduction on UK Equity Portfolios Included with Managed Futures Funds." International Review of Financial Analysis 18:5, 303-310. 


\section{ABOUT THE AUTHOR}

Kai-Hong Tee is a Senior Lecturer in Finance at Loughborough University Business School, United Kingdom. He worked previously as a Lecturer in Finance at the University of Aberdeen and as a Property Investment Marketing Consultant on both residential and commercial sectors in the international properties markets. His research interests involve the application of asymmetric risks on portfolio optimization, the study of liquidity risks, and efficient performance of managed futures and hedge funds. Other interests include exploring the hedging effectiveness of derivatives and the effectiveness of currency (portfolio) strategy for conditional hedging purposes. Dr. Tee's research has been published in the European Journal of Operational Research, International Review of Financial Analysis, and Applied Financial Economics. He has a BA in Economics and General Mathematics from the National University of Singapore, an MBA (with distinction) in finance from the Leeds University Business School, and a Ph.D. in Finance from Heriot-Watt University in Edinburgh, Scotland. 